\title{
Sonographic Transformation of Acrania to Anencephaly
}

\author{
${ }^{1}$ Raham Bacha, ${ }^{2}$ Syed Amar Gilani, ${ }^{3}$ Iqra Manzoor
}

\section{ABSTRACT}

Objective: To ascertain that acrania can lead to anencephaly.

Materials and methods: We commenced a cross-sectional study for a period of 41 months from 2013 to 2017. During routine ultrasound examination, we observed multiple cases of acrania in second trimester and third trimester. We followed 26 cases who failed to terminate their pregnancies and visited for reexamination. Changes in the brain matter, amniotic fluid volume, and echogenicity of the acrania fetuses were recorded and compared with the previous examination. Development of anencephaly was correlated with maternal age and advancement of gestational age. All the patients were examined transabdominally according to the American Institute of Ultrasound in Medicine (AIUM) guidelines for obstetrical ultrasound. Data were collected from the previous report and recent examination, by evaluating data with the help of IBM Statistical Package for the Social Sciences (SPSS) version 24 package, and the results were summarized.

Results: Pregnant women with diagnosed acrania fetus visited second time with a lapse of more than 4 weeks and were enrolled with mean age $25.73 \pm 8.80$. We observed 4 (15.4\%) acrania patients developed into anencephaly. Development of anencephaly was observed to be correlated with the advancement of gestational age. It was observed that acrania is more common in below 20 and above 30 age groups. Haziness of amniotic fluid is also observed to be related with acrania.

Conclusion: Anencephaly could be caused by multiple factors but acrania can lead to anencephaly with continuous exposure of brain matter and meninges to mechanical trauma and chemical activities of the amniotic fluid.

Clinical significance: To test the hypothesis of acrania to anencephaly and make a roadmap for upcoming researches on association of acrania with physical, environmental, and genetical factors.

Keywords: Acrania, Anencephaly, Brain tissue, Hazy amniotic fluid, Polyhydramnios.

How to cite this article: Bacha R, Gilani SA, Manzoor I. Sonographic Transformation of Acrania to Anencephaly. Donald School J Ultrasound Obstet Gynecol 2017;11(3):189-196.

Source of support: Nil

Conflict of interest: None

\footnotetext{
${ }^{1}$ Senior Lecturer, ${ }^{2}$ Dean, ${ }^{3}$ Student

1,3 University Institute of Radiological Sciences and Medical Imaging Technology, University of Lahore, Lahore, Pakistan

${ }^{2}$ Dean, Faculty of Allied Health Sciences, University of Lahore Lahore, Pakistan

Corresponding Author: Raham Bacha, Senior Lecturer University Institute of Radiological Sciences and Medical Imaging Technology, University of Lahore, Lahore, Pakistan Phone: +0333642255, e-mail: dr.rahambacha@gmail.com
}

\section{INTRODUCTION}

Acrania is a lethal condition characterized by the absence of cranial flat bone (vault) and poorly developed or disorganized brain tissues identified in direct contact with amniotic fluid. Acrania is a mesenchymal defect in which mesenchymal tissue fails to migrate to form cranial bone. Anencephaly (without brain) is a neural defect in which a substantial part of the brain is absent. It is neural tube defect (NTD) in which cranial end of the neural tube fails to close in first month of the pregnancy. It is believed that acrania, exencephaly, and anencephaly are not independent anomalies. Acrania or dysgraphia (absent cranial vault) results in the disintegration and resorption of the exposed brain (exencephaly) during the fetal period results in anencephaly. ${ }^{1-3}$

Fetus diagnosed with head anomalies especially acrania or anencephaly is a life-threatening condition because the prognosis of such fetuses is dismal. The prevalence of the head anomalies was estimated as 12 cases out of the 26,081 pregnant women, which is equivalent to $1 / 2,173 .{ }^{4}$ But another pictorial assay described the prevalence of acrania/anencephaly as 1 out of 1,000 . A study from the Turkish Perinatal Journal documented the prevalence of NTDs as 17.4 per 1,000 live births and that of anencephaly as 10.2 per 1,000 live births. ${ }^{5}$ Some other conditions like cleft lip and palate, spinal dysraphisms, cardiac, gastrointestinal, and urinary tract abnormalities may also be associated. ${ }^{6}$ A demographic study shows advanced maternal age is a most common predisposing factor for anencephaly; odds ratio of 2.043 and confidence interval 0.880 to 4.741 was estimated. ${ }^{7}$ Along with advanced maternal age, consanguinity, autumn winter conception, folic acid, and vitamin B12 deficiency, increasing use of anticonvulsant and antipyretic medicines is considered a risk factor.

A cadaveric study was carried out by Warren in $1951^{8}$ while dissecting nine acrania patients. He observed different degree of brain absence but complete formation of eyes, optic nerves, and peripheral nerves, i.e., vagus nerve, trigeminal nerve, etc. He concluded that anencephaly is closely related to acrania.

In some studies, ultrasound and autopsy results were correlated. In the other cases, laboratory data taken from amniocentesis were correlated. In a study, it is concluded that $8.67 \%$ of the cases with anencephaly had a normal karyotype and $6 \%$ chromosomal aberrations. Some of 
the acrania cases were related to aneuploidy, while a few were related to structural chromosomal abnormalities. ${ }^{7}$

Anencephaly is a NTD, although the causes of NTDs are still unknown. A comprehensive review article published by Halder in 2014 enlisted multiple factors responsible for the development of NTDs. The review concluded that about $10 \%$ sperms and up to $50 \%$ oocytes were found chromosomally abnormal. This results in pregnancy loss in about 50 to $60 \%$ of individuals. And about $15 \%$ of clinically recognized pregnancies underwent spontaneous abortion. It was believed that more than $50 \%$ of the early pregnancy lose occurs due to aneuploidy but $3 \%$ of live burn fetuses were associated with major congenital malformations. In the same review, it was found that about $60 \%$ of developmental defects are of unknown origin. Approximately $3 \%$ of all congenital defects were caused by environmental factors and $25 \%$ were believed to be caused by gene mutation caused by environment insults. Maternal age and different chemicals used in food as preservative or fertilizers were thought to be contributing factors. ${ }^{9}$

Ultrasound is the modality of choice for the early diagnosis of NTDs. A review was conducted on the early diagnosis of neural anomalies and sonoembryology. Different literatures were summarized in chronologic order and it was concluded that the detection of NTDs, especially acrania (exencephaly) and anencephaly, was initially made possible after 12 weeks of gestation with longitudinal two-dimensional and three-dimensional (3D) imaging but with the development of technology, state-of-the-art modalities and endoluminal sonography made it possible to see NTDs as early as 10 weeks of gestation. In 1990, nuchal translucency scan was introduced but now it is incorporated as a parameter in the early obstetrical ultrasound scan. Approximately $10 \%$ of all anomalies account for central nervous system anomalies and $50 \%$ of them could be detected in the first trimester. ${ }^{10}$

Embryologists presume that anencephaly could be developed due to the exposure of developing and differentiating brain during the embryonic period to amniotic fluid and mechanical trauma. The development of anencephaly in the late first trimester was described acrania by different authors; in their case reports, no detailed study has been made possible to be conducted on large sample size due to some limitations and rareness of the anomaly. Ultrasound series studies of multiple patients support the assumption that anencephaly is the end stage of progressive destruction of cerebral tissue in exencephalic fetuses. ${ }^{11}$

A population-based cohort study was conducted in southern Brazil on 29 acrania fetuses. It was concluded that anencephaly was diagnosed at about 21 weeks of gestation. Anencephaly was confirmed in $75.9 \%$ of cases after birth while the rest of them had different conditions like amniotic band disruption complex (6.9\%), hydranencephaly $(6.9 \%)$, merocrania $(3.4 \%)$, and holoprosencephaly (3.4\%). Sixteen anencephalic pregnancies were terminated either spontaneously with intrauterine fetal death or electively. Thirteen anencephalic fetuses were burnt alive but all of them died in the first week of life. It is concluded from the discussion that anencephaly is a fatal anomaly that leads to either intrauterine or extrauterine death. ${ }^{12}$

In our study, we followed pregnancies with acrania fetuses for a period of 4 weeks with the written informed consent of both the parents. Very few patients fail to terminate their pregnancy and were rescanned after $>4$ weeks. During rescanning patient, we found some unusual results. Some of the patients who were initially acrania after the lapse of 4 weeks appeared anencephalic with hazy amniotic fluid and suspended particles in it. This appearance proved that the mechanical and chemical irritation of brain matter in close contact with the amniotic fluid undergoes degeneration. The suspended particles are believed to be due to degenerative components.

\section{MATERIALS AND METHODS}

It was a cross-sectional observational study conducted in Gilani Ultrasound Center Afroasian Institute from October 2013 to March 2017. It was based on rare pathologic process; therefore, only 26 individuals were sampled after follow-up. The patients were selected with nonprobability sampling method. All the patients visited for the confirmation of known acrania fetus and scanned twice with a lapse of more than 4 weeks were included in this research. The study was aimed to look for the changes in exposed brain tissue; therefore, those patients who have not visited after 4 weeks for confirmation or have confirmed anencephalic fetus were excluded from the study. Toshiba Xario with convex transducer frequency ranging from 3 to $6 \mathrm{MHz}$ was used. Approval was taken from the institutional review board and ethical committee of the Afro-Asian Institute. All the patients who were included in this research were explained the procedure and aim of the research and written informed consent were signed.

The AIUM guidelines for obstetrics and gynecology ultrasound were followed during the study, which are routinely observed in this department. During examination, the privacy was kept at top priority, in close circumstances. By the confirmation of acrania fetus in first examination, the patient was advised to consult their gynecologist for termination of the pregnancy. Those patients who fail to terminate their pregnancy within 4 weeks were rescheduled for scanning. It was made 
sure that no data regarding patient identity or personal privacy will be disclosed. It was clearly mentioned in the consent form that the patient is not forced to follow-up for research purpose, but if she failed to terminate the pregnancy, then she must come for follow-up after more than 4 weeks to be enrolled in this research.

MS Word and Excel 2016 were used for the collection and organization of data, and SPSS IBM 21 version was used for the evaluation of data. Graphs and tables were made in Excel and SPSS software. The results were summarized in the form of graphs, tables, and charts. Descriptive data are explained in the form of frequency, mean, and standard deviation. Regression scatter plots were made to show correlation between different variables. Two-tailed Pearson's correlation was executed with SPSS to determine the significance level ( $\mathrm{p}$-value).

\section{RESULTS}

We examined 26 pregnant ladies of different age groups, mean age $25.73 \pm 8.8$, ranging from 14 to 26 years. All the enrolled pregnant women having acrania fetus were followed for second time scanning with a lapse of at least 4 weeks. At second examination, changes in fetal brain matter and amniotic fluid characteristics (hazy/clear) and volume (polyhydramnios/oligohydramnios/adequate) were recorded. Seventeen cases of acrania were excluded in this study because their pregnancies were terminated after first examination. Acrania was diagnosed at mean gestational age of $16.38 \pm 2.19$ (12-21) weeks. Second examination was executed at a mean gestational age of $24.46 \pm$ 4.70 (16-36) weeks with a mean lapse in weeks between

Table 1: Development of anencephaly

\begin{tabular}{lll}
\hline & Frequency & Percentage \\
\hline No & 22 & 84.6 \\
Yes & 4 & 15.4 \\
\hline
\end{tabular}

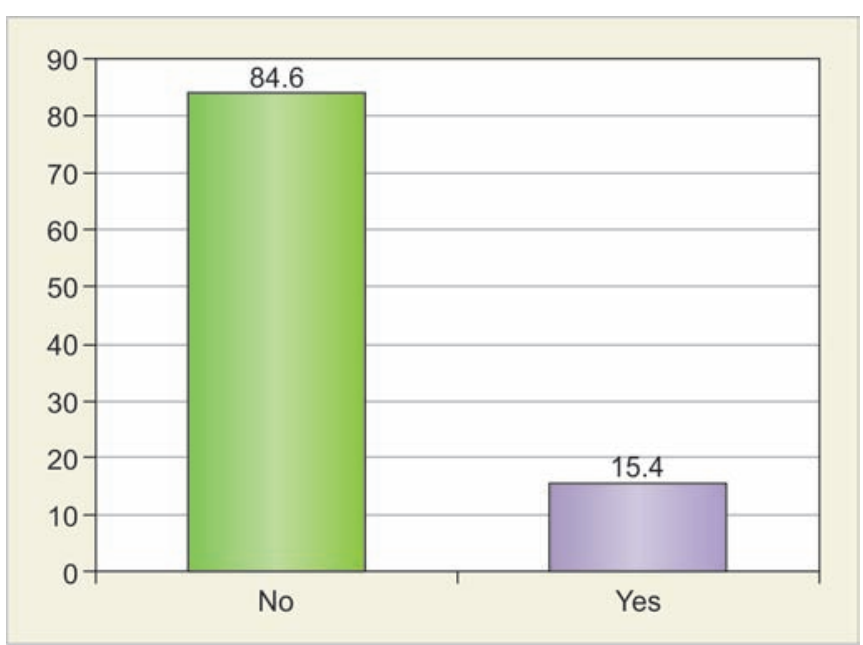

Graph 1: Percentage of development of anencephaly first and second examination of $8.03 \pm 4.38$ (4-21) weeks. Anencephaly was developed in $4(15.4 \%)$ cases while $22(84.6 \%$ ) remained unchanged (Table 1, and Graph 1). All the women were divided into five age classes with a class width of 5 . The classes mostly affected with acrania were below 20 years and above 35 years more frequently as compared with middle-aged classes while making a U-shaped curve (Table 2, and Graph 2). An increase in the amniotic fluid turbidity was noted with the advancement of gestational age of acrania baby. At first visit in 17 anencephalic (65.4\%) pregnancies, hazy amniotic fluid was observed but at second visit we observed hazy amniotic fluid in $23(88.5 \%$ ) (Table 3, and Graph 3). Similarly, the volume of amniotic fluid was also increased with gestational age, in acrania. At first visit, 1 (3.8\%) case was observed with oligohydramnios, 12 (46.15\%) with adequate amniotic fluid, and $14(53.84 \%)$ cases with polyhydramnios. During second sonographic examination, oligohydramnios observed in the same $1(3.8 \%)$ case, but amniotic fluid was increased in volume, $9(34.61 \%)$ cases observed with adequate amniotic fluid, and 16 (61.53\%) observed with polyhydramnios (Table 4, and Graph 4). A significant correlation was seen between the development of anencephaly and increase in lapse between first and second examination. Development of anencephaly was also observed to have significant correlation with the advancement of gestational age having "p-value" of 0.000 (Graph 5). We found no significant difference between parental blood relation and acrania.

Table 2: Maternal age groups with anencephaly

\begin{tabular}{lll}
\hline & Frequency & Percentage \\
\hline$<20.00$ & 10 & 38.5 \\
$20.00-24.00$ & 4 & 15.4 \\
$25.00-29.00$ & 2 & 7.7 \\
$30.00-34.00$ & 2 & 7.7 \\
$35.00+$ & 8 & 30.8 \\
\hline Total & 26 & 100.0
\end{tabular}

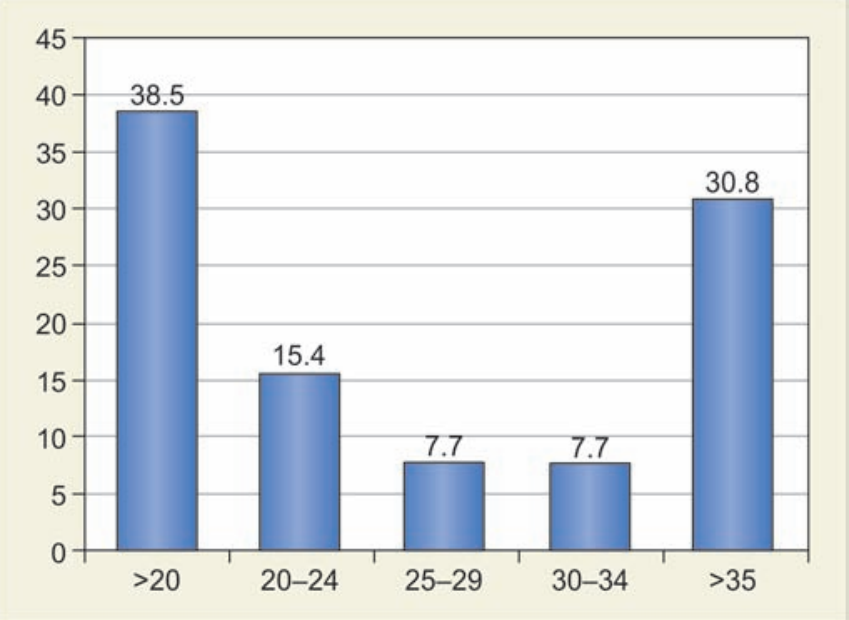

Graph 2: Percentage of maternal age groups with anencephaly 
Table 3: Amniotic fluid appearance at first and second examination

\begin{tabular}{|c|c|c|c|c|}
\hline & \multicolumn{2}{|c|}{$\begin{array}{l}\text { Amniotic fluid } \\
\text { characteristics at first visit }\end{array}$} & \multicolumn{2}{|c|}{$\begin{array}{c}\text { Amniotic fluid } \\
\text { characteristics at second visit }\end{array}$} \\
\hline & Frequency & Percentage & Frequency & Percentage \\
\hline Clear & 9 & 34.6 & 3 & 11.5 \\
\hline Hazy & 17 & 65.4 & 23 & 88.5 \\
\hline
\end{tabular}

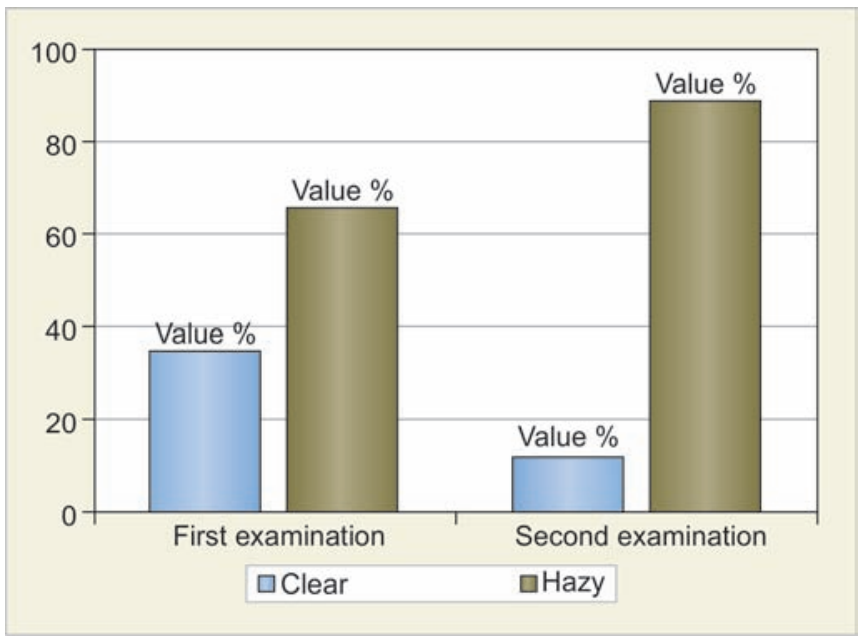

Graph 3: Amniotic fluid appearance at first and second examination

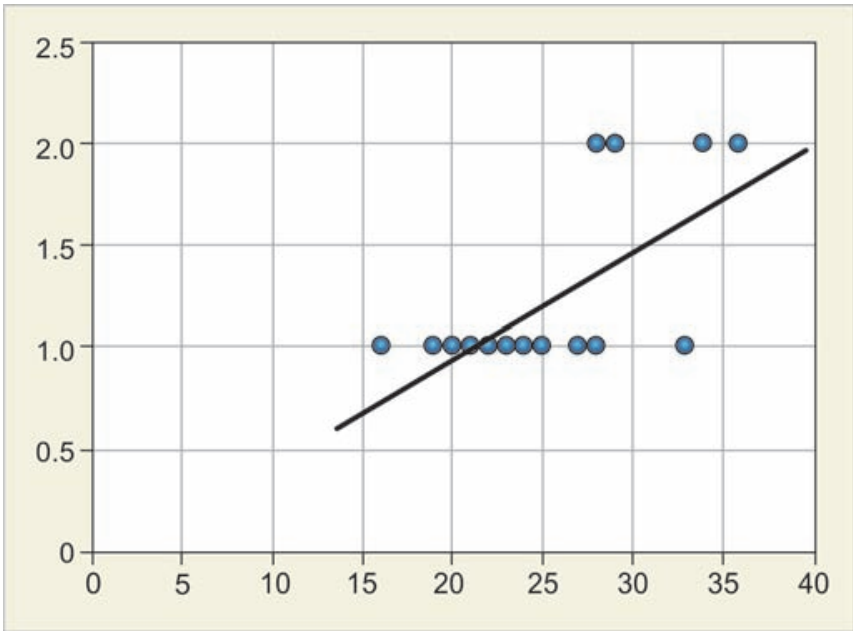

Graph 5: Development of anencephaly with advancing gestational age

Fourteen (53.8\%) Cousin (first and second cousis) marriages had acrania, while $12(46.2 \%)$ had no blood relation having acrania fetuses.

\section{DISCUSSION}

We started our research on the topic of sonographic sequelae of acrania to anencephaly in October 2013, with a 37-year-old female with 22 weeks pregnancy. On examination, the amniotic fluid was found hazy containing suspended particles and the fetus was alive with anencephaly. But her previous ultrasound images and
Table 4: Amniotic fluid volume in two visits at different occasion

\begin{tabular}{llllll}
\hline & \multicolumn{2}{c}{ First visit } & & \multicolumn{2}{c}{ Second visit } \\
\cline { 2 - 3 } \cline { 5 - 6 } & Frequency & Percent & & Frequency & Percent \\
\hline Oligohydramnios & 1 & 3.8 & & 1 & 3.8 \\
Adequate & 12 & 46.15 & & 9 & 34.61 \\
Polyhydramnios & 14 & 53.84 & & 16 & 61.53 \\
\hline
\end{tabular}

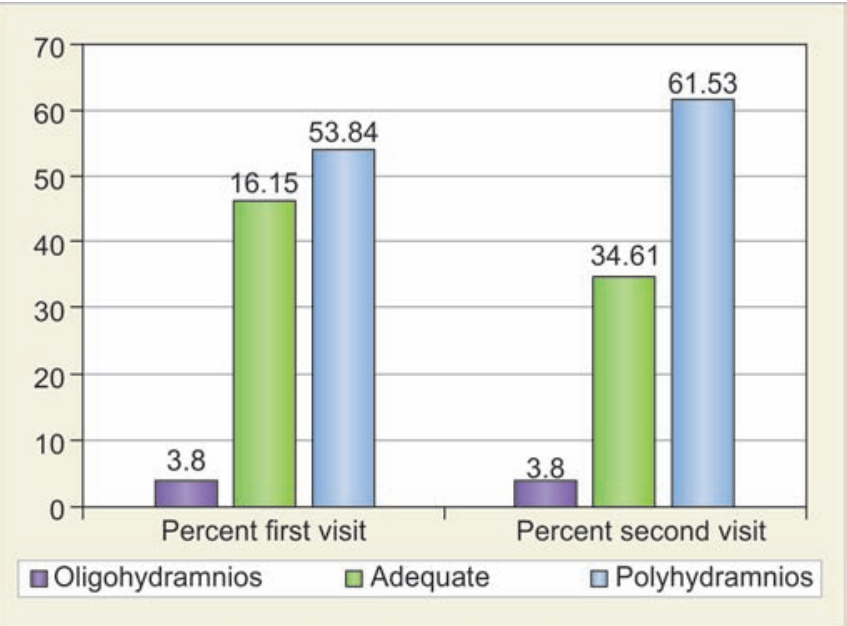

Graph 4: Amniotic fluid volume in two visits at different occasion

written report clearly showed acrania at 13 weeks gestation (Fig. 1). We started collection data on the hypothesis that brain mater in direct contact with the acidic medium of amniotic fluid in acrania fetuses undergoes degeneration. In such cases, degeneration and dissolution of the brain matter occur either by mechanical pressure or acidic environment of the amniotic fluid. Whatever the cause may be we wanted to ascertain that acrania may lead to anencephaly. To observe the sonographic appearance of sequelae, it occurs during the conversion of acrania to anencephaly and requires follow-up of the pregnant ladies with fetal acrania. It was really a difficult task and finally we found 26 cases in the duration of 41 months from October 2013 to March 2017.

A multisectorial study was conducted in 1997 by Johnson et $\mathrm{al}^{13}$ on the screening of anencephaly at 10 to 14 weeks of gestation (Fig. 2) in seven different hospitals of London. They performed ultrasound screening of 55,237 fetuses in their study and found 47 acrania with varying degrees of brain matter. They further followed these fetuses for detailed anatomic study at 18 to 22 weeks (Figs 3 to 10). They observed reduction in crown rump length (CRL) in $27 \%$ of the acrania cases with advancing gestational age. Reduction in CRL was assigned to the conversion of acrania to anencephaly. We followed cases of acrania for a period of more than 4 weeks but no specific gestational age was fixed for the first and followup examination. As it is rare event, we conveniently 


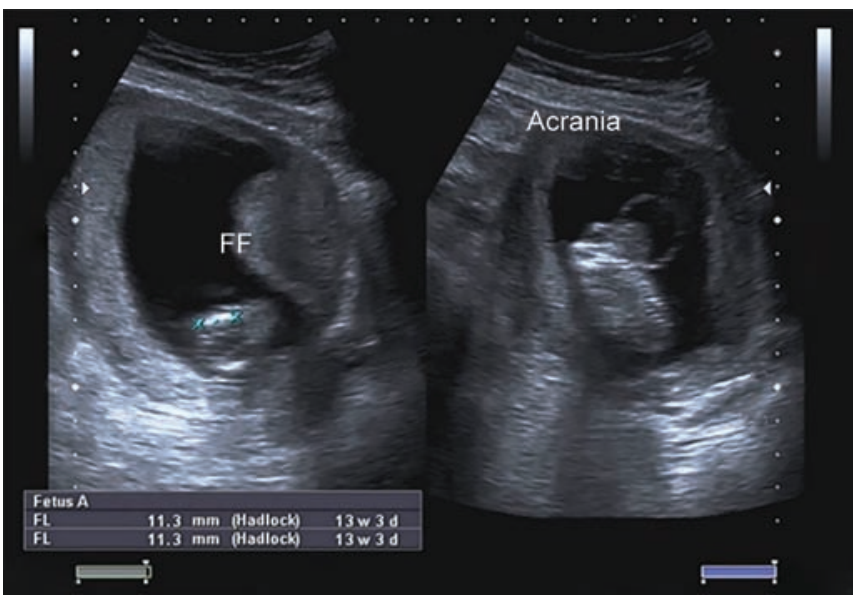

Fig. 1: Gestational age 13 weeks of acrania with polyhydramnios, brain matter freely floating in the amniotic fluid

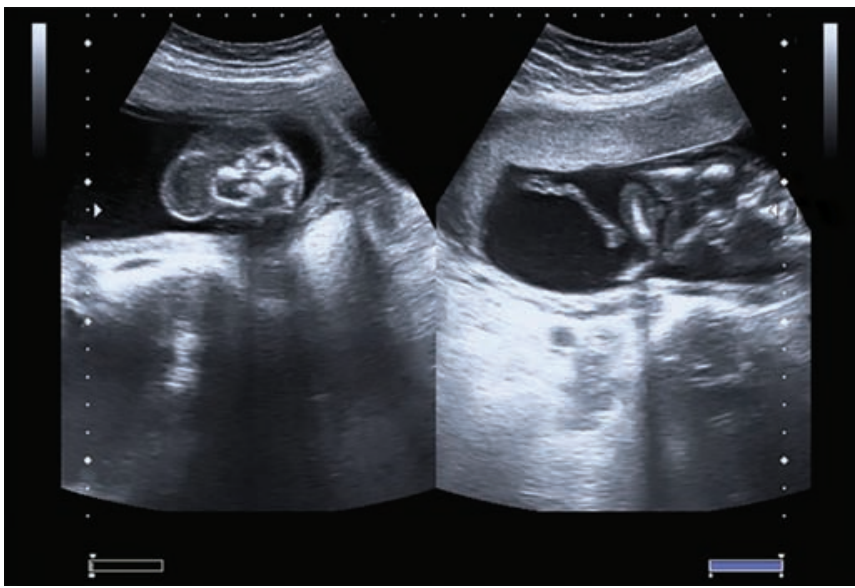

Fig. 3: Acrania of 16 weeks, 5 days, brain matter freely floating in the amniotic fluid

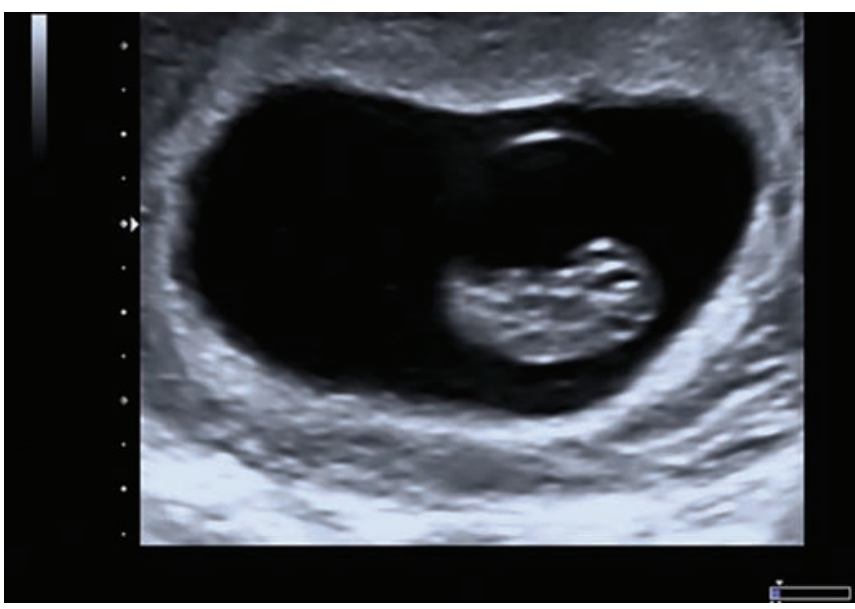

Fig. 5: Gestational age at 11 weeks with polyhydramnios

include all those acrania cases who visited for either routine obstetrical examination or expert opinion. We were observing directly brain matter and cranial bones, and direct observation revealed that $15.4 \%$ of acrania fetuses transformed to anencephaly, while $84.6 \%$ had no

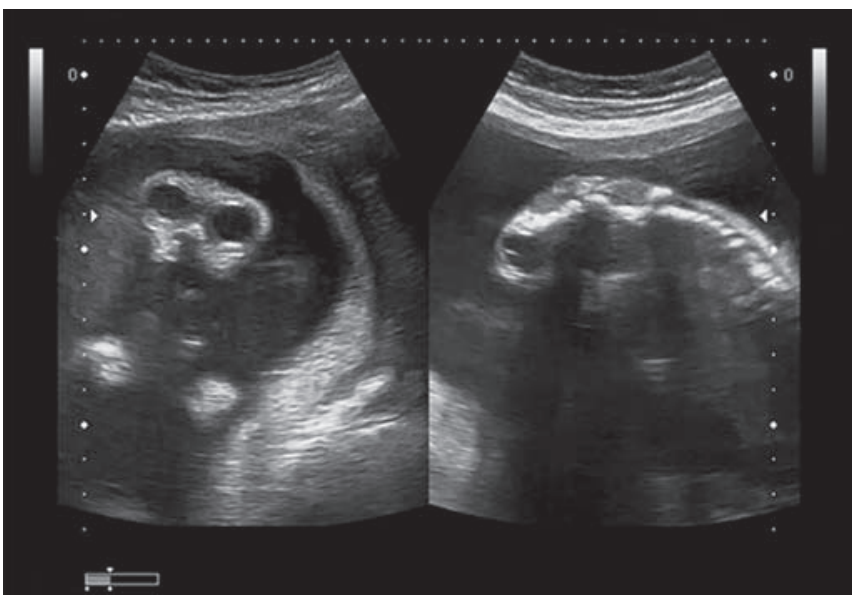

Fig. 2: Anencephaly (acrania in Fig. 1, followed up after 10 weeks)

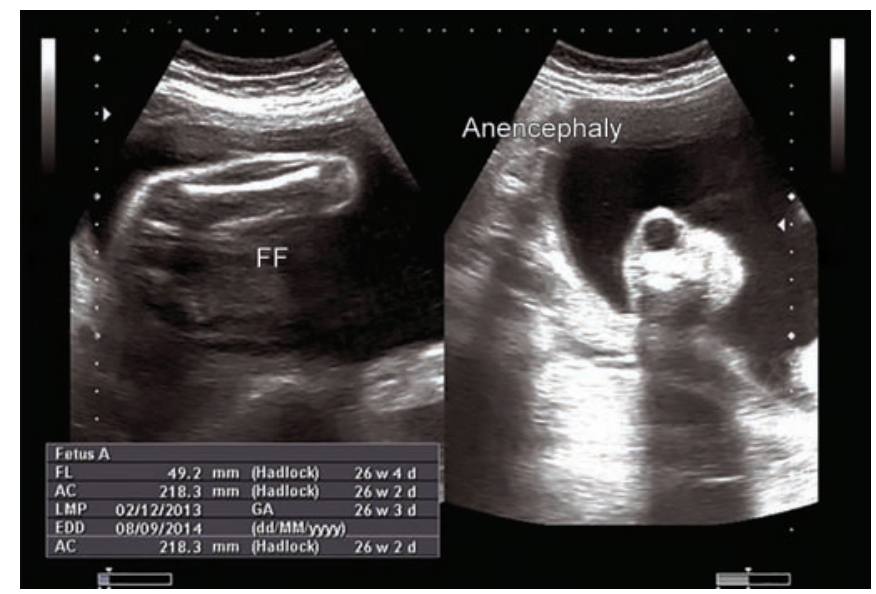

Fig. 4: Anencephaly (acrania in Fig. 3 followed after 9 weeks and 1 day)

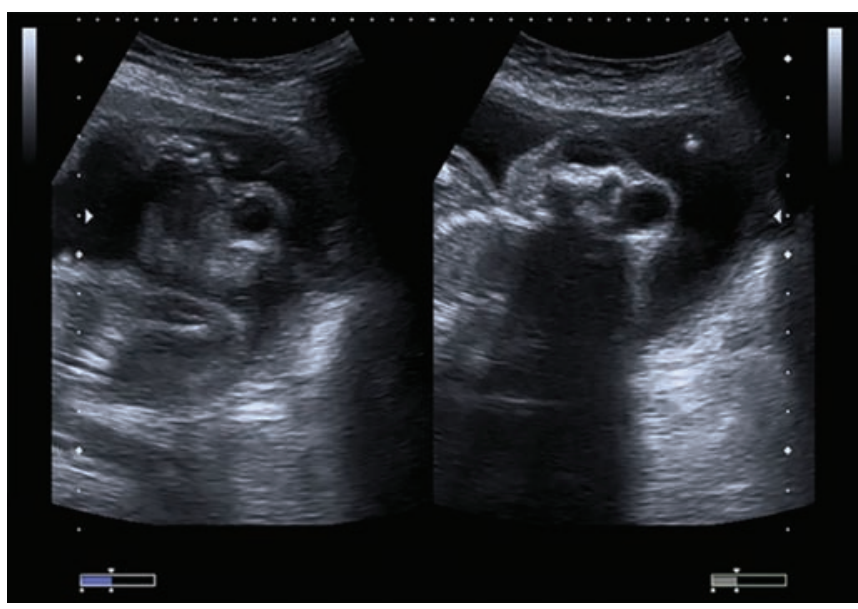

Fig. 6: Anencephaly (polyhydramnios case in Fig. 5 followed up after 9 weeks)

changes. It is obvious that acrania is not the only cause of anencephaly, and multiple factors contribute in the development of anencephaly.

A study was conducted on the factor effecting NTD in Tunis, Tunisia, from 2006 to 2009. Data were collected 


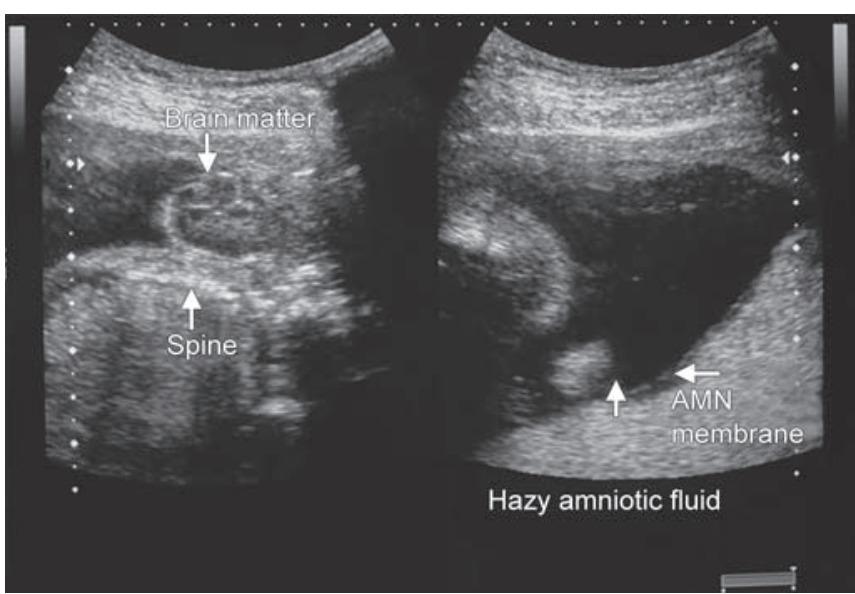

Fig. 7: Pregnancy of 19 weeks, 2 days, hazy amniotic fluid with polyhydramnios (amniotic fluid index $=26$ )

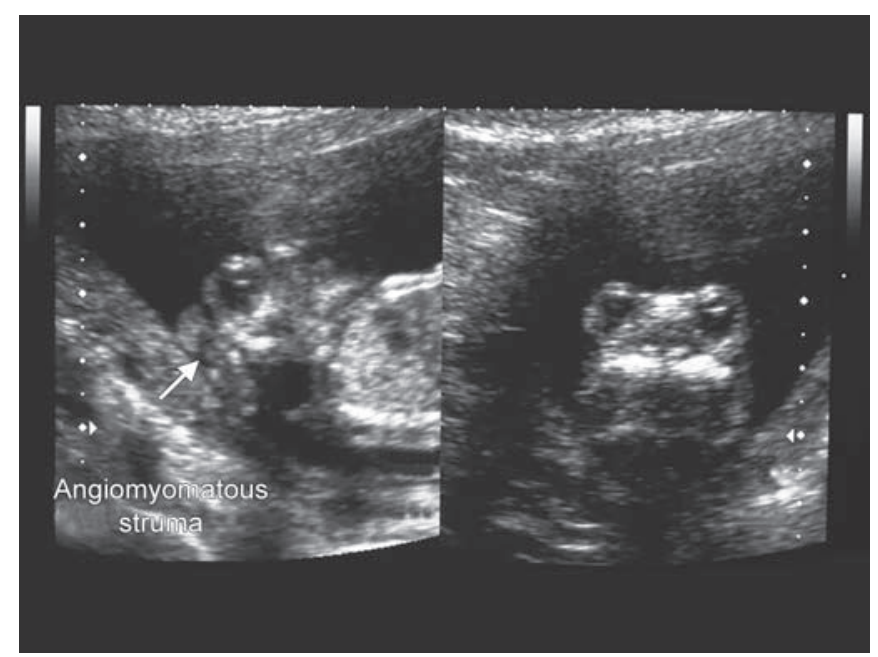

Fig. 9: Acrania case of 15 weeks and 2 days. True sagittal and transverse image of the fetal head and neck showing acrania with angiomyomatous struma and owl eye appearance

from the autopsy of 150 fetuses and concluded that the development of anencephaly is multifactorial but a large number of NTDs still remain undiagnosed, reason was their multifactorial genesis, and the role of many risk factors incompletely understood, such as advanced maternal age. ${ }^{7}$ Maternal folic acid deficiency was correlated with NTDs by Akhtar et $\mathrm{al}^{14}$ in Rawlakot Kashmir who found that about $85 \%$ of NTDs were associated with folic acid deficiency.

In our study, we divided the pregnant ladies into five classes of the same width and observed that the age group most affected by acrania is under 20 and the second class above 35 years. The graph of this type of tendency makes a characteristic curve described by other studies as U-shaped curve. A meta-analysis aimed to describe the relation of maternal age with NTD and it was evident that there is a U-shaped curve between maternal age and NTD. In advanced maternal age, spina bifida is more common, but under 20, maternal age has

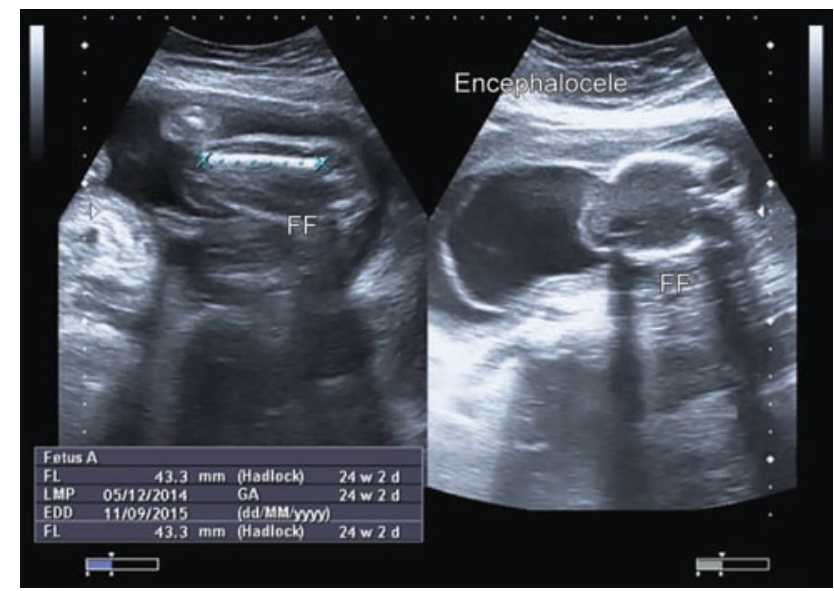

Fig. 8: Exencephaly, 24 weeks pregnancy with defected skull bones and brain matter along with meninges freely floating (FF) in the amniotic fluid
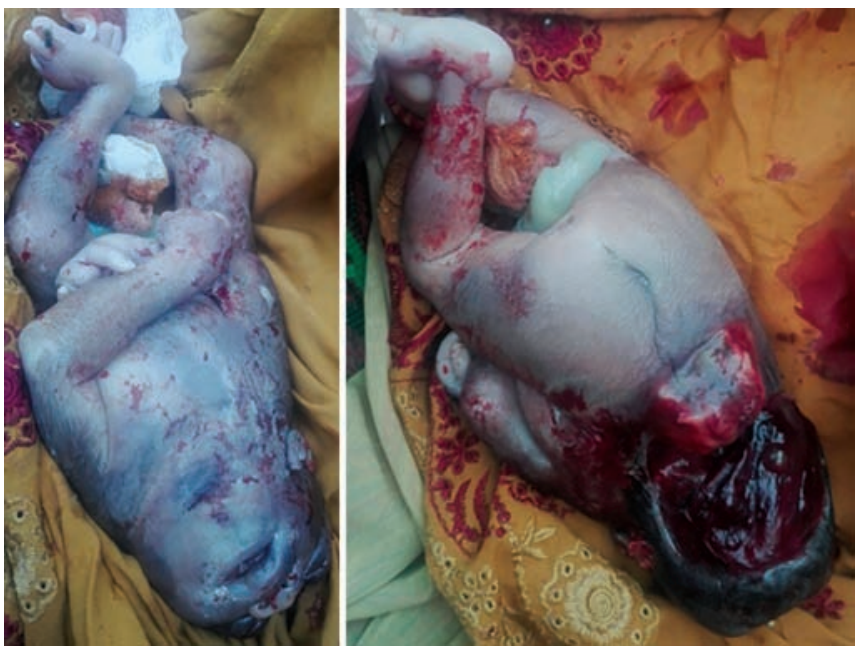

Fig. 10: Anencephalic fetus delivered through C-section

more probability of anencephaly, and this result supports our data. ${ }^{15}$

In our research, the hazy appearance of amniotic fluid during second visit was found in $88.5 \%$ of cases associated with anencephaly. A study was conducted by Cafici and Sepulveda ${ }^{16}$ on nine anencephaly fetuses. They aimed to describe the association of amniotic fluid appearance in first trimester with anencephaly. They divided amniotic fluid appearance into three grades and found that about $89 \%$ of the anencephaly was associated with echogenic amniotic fluid in the first trimester.

Another study was conducted for a long period (9 years) of time on a large sample size $(>400,000)$ to describe other malformations associated with NTDs. The study was confined to geographically defined area of the Strasbourg, France. It was concluded that 1/913 had NTDs. Ninety $(20.5 \%)$ were associated with other malformations, but $79.5 \%$ were isolated cases of NTDs. Fetuses having other malformation associated with 
neural defects were further subdivided into those with recognizable chromosomal defects $(2.5 \%)$ and with nonchromosomal defects $(5.2 \%)$, but $12.7 \%$ were without recognizable conditions. This research was useful for epidemiological data. ${ }^{17}$

We observed anencephalic fetuses at two different occasions lapsed with at least 4 weeks. At first visit, we observed polyhydramnios in $12(46.15 \%)$ while it was normal in 14 (53.84\%) cases. During our second observation at the second visit of the patient with lapse of more than 4 weeks, polyhydramnios was found in 16 cases (61.53\%), but in 9 cases (34.61\%), amniotic fluid was normal while in 1 case $(3.8 \%)$, there was oligohydramnios. A controversy is found in the association of amniotic fluid volume and acrania. A study conducted on 10 anencephalic fetuses showed polyhydramnios in $30 \%$ of cases. ${ }^{18}$ Another study published by the Turkish Society of Ultrasound conducted on 63 fetuses resulted that $14.5 \%$ of the anencephaly cases were associated with polyhydramnios. ${ }^{5}$

No information was available for the environmental factor or substance causing acrania, due to cultural limitation to disclose personal information. Most of the patients were primigravida, but some of them had a history of recurrent abortion. The most important limitations of the study were rareness and lethalness of the anomaly. Once acrania is diagnosed, the parents decide to terminate the pregnancy soon. It is therefore difficult to follow the fetus for sequential sonographic examinations, although Gilani Ultrasound Center provides basic ultrasound course, which is especially attractive for people related to obstetrics and gynecology. These students achieve basic knowledge and refer their complicated cases for expert opinion to their teachers in this center. This benefit particularly aided in the sample size with cranial anomalies but still we followed only a few cases for sequential examination. Acrania fetus have excessive vigorous moments which are expected to be due to irritation of the brain matter in open contact with amniotic fluid. It became difficult to focus on a particular structure for anatomic detail, due to excessive fetal moments. Hazy amniotic fluid is a challenge in the prenatal diagnosis of acrania and potentially becomes the source of many pitfalls. Real-time two-dimensional sonography is better in the visualization of brain matter in hazy amniotic fluid than gray-scale still image. The $3 \mathrm{D}$ and four-dimensional with volume rendering and surface rendering are considered more productive than conventional two-dimensional sonography. ${ }^{19}$

Optimum scanning techniques and protocols should be used to scan acrania cases with hazy amniotic fluid. Changing frequency, gain, and focal point are the frequent controls, to acquire optimum image by its adjustment for better visualization of anatomic structures. Different transducer access and approaches are needed to bitterly visualize the brain matter in the hazy amniotic fluid.

\section{CONCLUSION}

It is concluded that along with other causes of anencephaly, acrania can also develop into anencephaly. In light of previous research data, folic acid deficiency has profound effect on the fetal NTDs.

\section{RECOMMENDATIONS}

Ultrasound has the potential to detect morphological appearance of structures in the fetus with meticulous examination. We can develop more soft markers with great accuracy to examine the fetus very keenly. It is recommended to consider the fetus as an independent individual, not merely a part of the maternal body.

\section{REFERENCES}

1. Hagen-Ansert SL. Textbook of diagnostic sonography. Elsevier Health Sciences; 2017.

2. Kurjak A, Chervenak FA. Donald school textbook of ultrasound in obstetrics and gynecology. 3rd ed. Jaypee Brothers, Medical Publishers Pvt. Limited; 2011. p. 249

3. Hata T, Uketa E, Tenkumo C, Hanaoka U, Kanenishi K, Tanaka $\mathrm{H}$. Three-and four-dimensional HDlive rendering image of fetal acrania/exencephaly in early pregnancy. J Med Ultrasonics 2013;40(3):271-273.

4. Hassan SM, Ramadan W, Kamel AM. Prevalence of central nervous system malformations in Egypt: a hospital-based study. J Evidence Based Women's Health J Soc 2016 Aug;6(3): 106-109.

5. Tunç SY, Ağaçayak E, İçen MS, Fındık FM, Yıldızbakan A, Yücesoy B, Yalınkaya A. Anencephaly and coexisting malformations: analysis of 35 cases. PERINATAL 2015 Dec;23(3): 175-179.

6. Radulescu M, Ulmeanu EC, Nedelea M, Oncescu A. Prenatal ultrasound diagnosis of neural tube defects. Pictorial essay. Med Ultrason 2012 Jun;14(2):147-153.

7. Kitova T, Milkov D, Kitov B, Kilova K, Gaigi S. Demographic factors and associated anomalies in fetuses with neural tube defects. Pteridines 2013 Dec;24(3-4):257-263.

8. Warren HS. Acrania induced by anencephaly. Anat Rec 1951;111(4):653-667.

9. Halder A. Lethal developmental defects: an overview. Open J Obstet Gynecol 2014;4(16):1006.

10. Blaas HG, Eik-Nes S. Sonoembryology and early prenatal diagnosis of neural anomalies. Prenatal Diagn 2009 Apr;29(4):312-325.

11. Bianchi D, Crombleholme T, Alton MD, Malone F. Fetology: diagnosis and management of the fetal patient, $2 \mathrm{n}$ ed. New York: McGraw-Hill Education; 2010. p. 1056

12. Pelizzari E, Valdez CM, Picetti JDS, Cunha ACD, Dietrich C, Fell PRK, Targa LV, Zen PR, Rosa RF. Characteristics of fetuses evaluated due to suspected anencephaly: a population-based 
cohort study in southern Brazil. Sao Paulo Med J 2015 Mar-Apr;133(2):101-108.

13. Johnson S, Sebire N, Snijders R, Tunkel S, Nicolaides K. Ultrasound screening for anencephaly at 10-14 weeks of gestation. Ultrasound Obstet Gynecol 1997 Jan;9(1):14-16.

14. Akhtar M, Qaiser QA, Latif A. Antenatal diagnosis of anencephaly to determine the prevalence and its correlation with folic acid deficiency by using peripheral blood picture in District Poonch, Azad Kashmir. Methods 2015.

15. Vieira AR, Castillo TS. Maternal age and neural tube defects: evidence for a greater effect in spina bifida than in anencephaly. Rev Med Chil 2005 Jan;133(1):62-70.
16. Cafici D, Sepulveda W. First trimester echogenic amniotic fluid in the acrania-anencephaly sequence. J Ultrasound Med 2003 Oct;22(10):1075-1079.

17. Stoll C, Dott B, Alembik Y, Roth MP. Associated malformations among infants with neural tube defects. American J Med Genet Part A 2011 Feb;155(3):565-568.

18. Reddy KJ, Ramanappa MV. Anencephaly and its associated anomalies in antenatal scans. J Evid Based Med Healthc 2016; 3(23):1033-1035.

19. Pooh RK, Kurjak A. 3D/4D sonography moved prenatal diagnosis of fetal anomalies from the second to the first trimester of pregnancy. Taylor \& Francis; 2012. 